\title{
Non-invasive estimation of the mean pressure difference in aortic stenosis by Doppler ultrasound
}

\author{
DAG TEIEN, KJELL KARP, PETER ERIKSSON \\ From the Departments of Clinical Physiology and Internal Medicine, University Hospital, Umed, Sweden
}

SUMMARY The mean pressure difference across the valve in aortic stenosis is an indicator of the severity of the obstruction to flow. Non-invasive determination of the mean pressure gradient by Doppler ultrasonography is, however, complicated by the squared relation between instantaneous velocities and pressure differences. The validity of a new simple formula for calculation of the mean pressure difference from the peak pressure difference was evaluated in 26 patients with aortic stenosis. The formula is: $\Delta \mathrm{p}_{\text {mean }}=0.64 \Delta \mathrm{p}_{\text {peak }}$, where $\Delta \mathrm{p}_{\text {mean }}$ is the mean pressure gradient and $\Delta \mathrm{p}_{\text {peak }}$ the peak pressure gradient. There was a close correlation between the mean pressure differences determined by application of the formula to the peak pressure differences measured at catheterisation and the mean pressure differences obtained by planimetry $(r=0.97, \operatorname{SEE}=$ $4.7 \mathrm{~mm} \mathrm{Hg}$ ). The correlation between mean pressure differences determined by continuous wave Doppler ultrasound and the formula and those measured by planimetry was also close $(r=0.91$, $\mathrm{SEE}=7.6 \mathrm{~mm} \mathrm{Hg}$ ) and only three patients showed a difference between the two methods of $>10 \mathrm{~mm} \mathrm{Hg}$.

The new formula is a simple and reliable means of estimating the mean pressure difference from Doppler recordings and it facilitates the comparison of Doppler and catheterisation data.

Assessment of the severity of aortic stenosis is of great clinical importance because flow obstruction can be life threatening. Determination of the transvalvar pressure difference provides important information about the severity of the obstructive lesion. The systolic flow velocity can be measured by continuous wave Doppler echocardiography and the maximum velocity can be transformed into the peak pressure difference by a simplified Bernoulli formula. ${ }^{1}$ The Doppler derived peak pressure difference is, however, conceptually different from both the peak to peak and mean pressure difference routinely obtained at cardiac catheterisation and the three measurements may differ considerably. ${ }^{2-10}$ The mean pressure difference offers a more accurate estimation of the severity of stenosis because it takes into account changes of the pressure difference throughout systole, and for this reason it is usually included in hydraulic orifice formulas. ${ }^{1112}$ The squared relation between the instantaneous flow velocities and the pressure differences, however,

Requests for reprints to Dr Dag Teien, Department of Clinical Physiology, University Hospital, S-901 85 Umeả, Sweden.

Accepted for publication 21 July 1986 makes Doppler determination of the mean pressure difference time consuming and subject to errors.

If the difference between a simultaneously recorded left ventricular and aortic pressure curve (the systolic pressure drop) is plotted the resulting curve shows a configuration similar to a sine wave. If this algorithm is appropriate it would provide a simple means for estimation of the mean pressure difference from the peak pressure difference.

A sine wave is mathematically written as,

$$
\mathrm{y}=\mathbf{a} \sin \mathbf{k t}
$$

The area (A) under the curve is expressed as,

$$
A=\int_{0}^{T} a \sin k t d t
$$

Applied to a pressure curve, a represents the peak instantaneous pressure difference $\left(\Delta \mathrm{p}_{\text {peak }}\right), \mathrm{T}$ represents the left ventricular ejection time, and $k$ is $\pi / T$. Solving the integral equation,

$$
\mathrm{A}=2 \mathrm{a} \mathrm{T} / \pi
$$

If $\mathrm{b}$ represents the mean pressure drop $\left(\Delta \mathrm{p}_{\text {mean }}\right)$ the area can also be expressed as,

$$
\mathrm{A}=\mathrm{bT}
$$


Combining equations (3) and (4) gives,

$$
\mathrm{b}=2 \mathrm{a} / \pi
$$

Thus,

$$
\Delta \mathrm{p}_{\text {mean }}=2 / \pi\left(\Delta \mathrm{p}_{\text {peak }}\right)
$$

The mean pressure gradient can thus be expressed: $\Delta \mathrm{p}_{\text {mean }}=0.64 \Delta \mathrm{p}_{\text {peak }}$.

The present study was undertaken to evaluate the accuracy of this formula when it was applied to invasively measured and Doppler derived transvalvar pressure differences in patients with aortic stenosis.

\section{Patients and methods}

\section{PATIENTS}

Twenty six consecutive adult patients referred for evaluation of suspected aortic stenosis were included in the study. There were fifteen men and eleven women whose ages ranged from 49 to 77 years (mean 62). Fifteen patients had aortic stenosis with no or only minimal regurgitation, eight had moderate or moderately severe regurgitation, and three had severe regurgitation according to angiography. ${ }^{13}$ Fourteen patients had concomitant mitral regurgitation, which was considered to be minimal in twelve and moderate in two. ${ }^{13}$ Radionuclide left ventricular ejection fractions, obtained from equilibrium studies in the left anterior $45^{\circ}$ projection, ranged from 0.23 to 0.80 (mean (1 SD) $0.55(0.13)$ ). All patients gave informed consent.

\section{CARDIAC CATHETERISATION}

Left heart catheterisation was performed via the retrograde brachial approach by a modified Seldinger technique in accordance with the routine of the hospital. No premedication was given. Pressures were recorded by liquid filled catheters connected to mechanoelectrical transducers interfaced with an UV recorder and calibrated against a hydrostatic standard. Simultaneous left ventricular and ascending aortic pressure curves were obtained by a dual catheter technique.

\section{DOPPLER MEASUREMENTS}

Continuous wave Doppler examinations were performed by a Pedof system with a $2.0 \mathrm{MHz}$ nonimaging transducer (Vingmed $A / S$ ). The examinations were carried out within an hour of the subsequent invasive measurements. Maximum and mean flow velocities were recorded on a Mingograph recorder (Siemens-Elema). Spectral analysis was not available. Repeated recordings of the aortic valve systolic velocity was attempted at the suprasternal, supraclavicular, right parasternal, apical, and subcostal transducer positions. The search from the right sternal border was made with the patient in the right lateral position and from the apex with the patient in the left lateral position. Recognition of maximum blood flow velocities was aided by the direct audio output. The highest audible frequency without lower frequencies and with velocity curves with regular smooth profiles was regarded as indicating optimal transducer position. No correction was used to compensate for the presumed angle between the ultrasonic beam and the maximal aortic jet.

\section{DATA ANALYSIS}

Analyses of cardiac catheterisation and Doppler data were performed independently and the results were not compared until after the study was completed.

Catheterisation data were used to obtain the peak pressure difference, which was taken to be the largest instantaneous pressure difference measured between the left ventricular and aortic pressure curves. The mean pressure difference was calculated by planimetry of the area between the two pressure curves. In addition, the mean pressure difference was calculated from equation (6). The pressure differences were calculated from five representative beats and averaged.

Doppler recordings were analysed to obtain the peak instantaneous systolic flow velocity $\left(v_{\text {peak }}\right)$, and the peak pressure difference $\left(\Delta \mathrm{p}_{\text {peak }}\right)$ was calculated from the modified Bernoulli equation, $\Delta \mathrm{p}_{\text {peak }}=4\left(\mathrm{v}_{\text {peak }}\right)^{2}{ }^{1}$ The mean pressure difference was calculated from the peak pressure difference using equation (6).

\section{STATISTICAL METHODS}

Paired $t$ test and correlation and linear regression analysis were used to compare the data. Agreement between methods was assessed according to the method of Bland and Altman. ${ }^{14}$

\section{Results}

Table 1 shows individual catheterisation data. Table 2 shows the relation between the mean pressure difference and the peak pressure difference measured at catheterisation in the present study and in the studies of Krafchek et $a l^{5}$ and Zhang et al. ${ }^{9}$ The resulting regression coefficients were $0 \cdot 65,0.68$, and 0.66 respectively, close to the assumed value of 0.64 . A paired $t$ test did not demonstrate any significant difference between $\Delta \mathrm{p}_{\text {mean }}$ and $0 \cdot 64 \Delta \mathrm{p}_{\text {peak }}$. Figure 1 shows the similarity of the results obtained by the two methods in our study. There was no obvious correlation between the difference and the mean of the two methods, and only one patient showed a discrepancy between the two measurements that 
Table 1 Individual catheterisation and Doppler pressure gradients

\begin{tabular}{|c|c|c|c|c|c|c|}
\hline \multicolumn{5}{|c|}{ Catheterisation gradients } & \multicolumn{2}{|c|}{ Doppler gradients } \\
\hline $\begin{array}{l}\text { Patient } \\
\text { No }\end{array}$ & $\begin{array}{l}\text { Peak gradient } \\
\text { (mm Hg })\end{array}$ & $\begin{array}{l}\text { Peak to peak gradient } \\
(\mathrm{mm} \mathrm{Hg})\end{array}$ & $\begin{array}{l}\text { Mean gradient } \\
(\mathrm{mm} \mathrm{Hg})\end{array}$ & $\begin{array}{l}0.64 \times \text { peak gradient } \\
(\mathrm{mm} \mathrm{Hg})\end{array}$ & $\begin{array}{l}\text { Peak gradient } \\
(\mathrm{mm} \mathrm{Hg})\end{array}$ & $\begin{array}{l}0.64 \times \text { peak gradient } \\
(\mathrm{mm} \mathrm{Hg})\end{array}$ \\
\hline $\begin{array}{r}1 \\
2 \\
3 \\
4 \\
5 \\
6 \\
7 \\
8 \\
9 \\
10 \\
11 \\
12 \\
13 \\
14 \\
15 \\
16 \\
17 \\
18 \\
19 \\
20 \\
21 \\
22 \\
23 \\
24 \\
25 \\
26\end{array}$ & $\begin{array}{r}82 \\
60 \\
90 \\
104 \\
66 \\
70 \\
78 \\
100 \\
28 \\
68 \\
70 \\
43 \\
23 \\
74 \\
72 \\
96 \\
108 \\
104 \\
116 \\
86 \\
48 \\
120 \\
90 \\
44 \\
40 \\
36\end{array}$ & $\begin{array}{r}42 \\
36 \\
52 \\
76 \\
44 \\
52 \\
56 \\
72 \\
25 \\
46 \\
57 \\
12 \\
21 \\
48 \\
56 \\
84 \\
86 \\
48 \\
102 \\
63 \\
40 \\
112 \\
40 \\
20 \\
30 \\
25\end{array}$ & $\begin{array}{l}53 \\
33 \\
64 \\
63 \\
50 \\
49 \\
42 \\
69 \\
18 \\
41 \\
41 \\
16 \\
16 \\
44 \\
43 \\
62 \\
64 \\
61 \\
71 \\
51 \\
33 \\
80 \\
50 \\
24 \\
21 \\
22\end{array}$ & $\begin{array}{l}52 \\
38 \\
58 \\
67 \\
42 \\
45 \\
50 \\
64 \\
18 \\
44 \\
45 \\
28 \\
15 \\
47 \\
46 \\
61 \\
69 \\
67 \\
74 \\
55 \\
31 \\
77 \\
58 \\
28 \\
25 \\
23\end{array}$ & $\begin{array}{r}71 \\
46 \\
64 \\
96 \\
67 \\
81 \\
81 \\
96 \\
25 \\
41 \\
58 \\
27 \\
20 \\
61 \\
81 \\
96 \\
108 \\
96 \\
92 \\
71 \\
44 \\
112 \\
85 \\
44 \\
46 \\
36\end{array}$ & $\begin{array}{l}46 \\
29 \\
41 \\
61 \\
43 \\
52 \\
52 \\
61 \\
16 \\
26 \\
37 \\
17 \\
13 \\
39 \\
52 \\
61 \\
69 \\
61 \\
59 \\
45 \\
28 \\
72 \\
54 \\
28 \\
29 \\
23\end{array}$ \\
\hline
\end{tabular}

Table 2 The relation between the mean pressure difference and the peak pressure difference expressed as regression equations

\begin{tabular}{lll}
\hline & Regression equations & $\begin{array}{l}\text { Paired } t \text { test between } \\
0.64 \Delta \mathrm{p}_{\text {peak }} \text { and } \Delta \mathrm{p}_{\text {mean }}\end{array}$ \\
\hline Present study & $\Delta \mathrm{p}_{\text {mean }}=0.65 \Delta \mathrm{p}_{\text {peak }}-2.4$ & $\mathrm{t}=1.579$ \\
Krafchek et al & $\mathrm{r}=0.97, \mathrm{SEE} 4.7 \mathrm{~mm} \mathrm{Hg}$ & $\mathrm{DF}=25$ \\
& $\Delta \mathrm{p}_{\text {mean }}=0.66 \Delta \mathrm{p}_{\text {peak }}-0.66$ & $\mathrm{t}=0.290$ \\
Zhang et al & $\mathrm{r}=0.93, \mathrm{SEE} 8.0 \mathrm{~mm} \mathrm{Hg}$ & $\mathrm{DF}=23$ \\
& $\Delta \mathrm{p}_{\text {mean }}=0.68 \Delta \mathrm{p}_{\text {peak }}+0.2$ & $\mathrm{t}=1.230$ \\
& $\mathrm{r}=0.97$, SEE $4.7 \mathrm{~mm} \mathrm{Hg}$ & $\mathrm{DF}=21$
\end{tabular}

DF, degrees of freedom; SEE, standard error of the estimate.

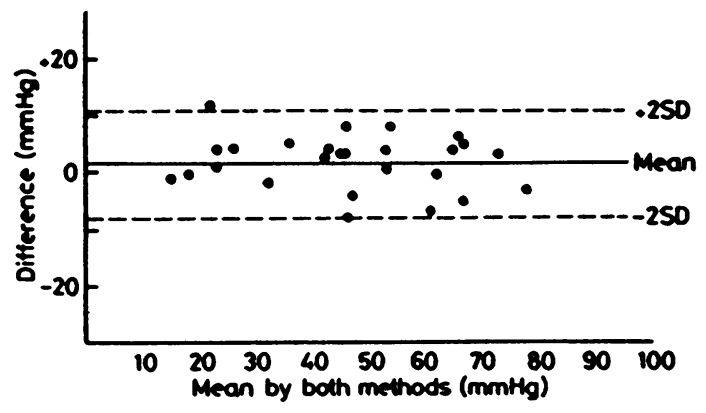

Fig 1 Difference of the mean pressure gradient obtained by application of the equation (6) to the catheterisation peak pressure gradient and the mean pressure gradient measured by planimetry plotted against the mean by both methods. exceeded $8 \mathrm{~mm} \mathrm{Hg}$.

Table 1 also shows individual Doppler data. Ade- $\frac{T}{O}$ quate Doppler recordings were obtained in 23 patients and no patient was excluded because of $N$ imperfect tracings. Figure 2 shows the relation between the Doppler derived peak pressure gradients and the gradients measured at catheterisation $(r=0.93, \mathrm{SEE}=9.8 \mathrm{~mm} \mathrm{Hg})$. Figure 3 shows the mean pressure gradients obtained from Doppler data by application of the equation (6) compared with invasive mean pressure gradients obtained by planimetry $(r=0.91, S E E=7.6 \mathrm{~mm} \mathrm{Hg})$. Figure 4 demonstrates the close approximation of the results obtained by the two methods; a paired $t$ test did not show any significant difference between them. Only 


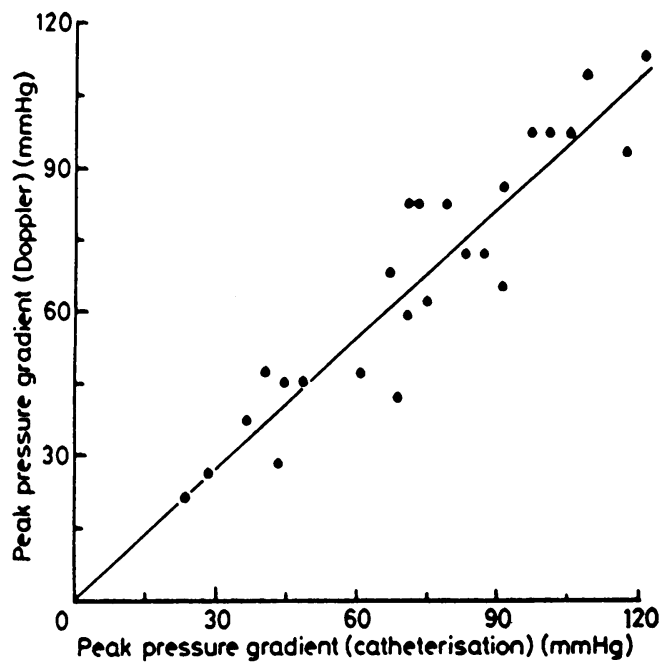

Fig 2 Relation between the peak pressure gradient obtained at catheterisation and the Doppler derived peak pressure gradient. $r=0.93, y=0.91 x+0.2, S E E 9.8 \mathrm{~mm} \mathrm{Hg}$, $n=26$.

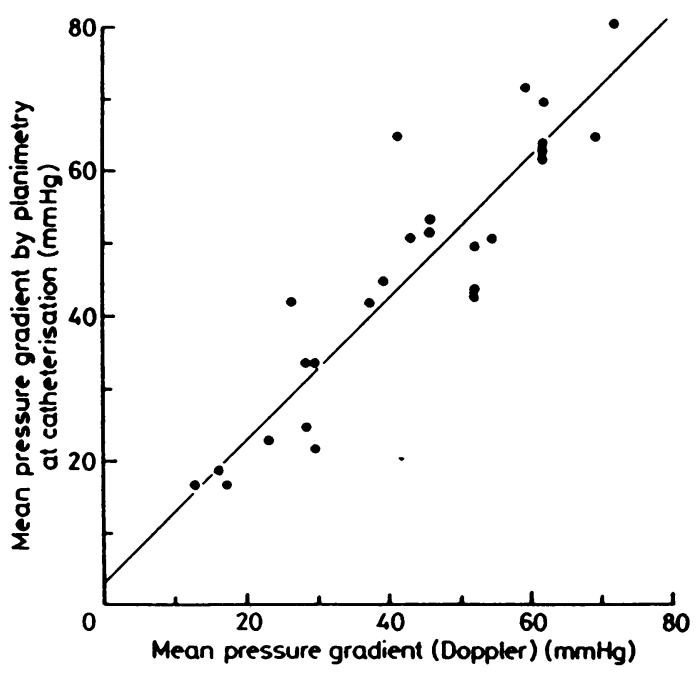

Fig 3 Relation between the mean pressure gradient obtained by application of the equation (6) to the Doppler derived peak pressure gradient and the mean pressure gradient obtained by planimetry at catheterisation. $r=0.91$, $y=0.99 x+3 \cdot 2, S E E 7.6 m m ~ H g, n=26$.

three patients showed a difference between the methods of $>10 \mathrm{~mm} \mathrm{Hg}$.

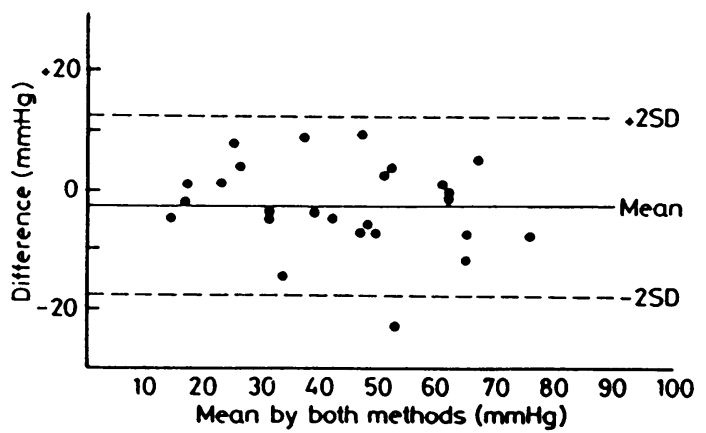

Fig 4 Difference of the mean pressure gradient obtained by application of equation (6) to the Doppler derived peak pressure gradient and the catheterisation mean pressure gradient measured by planimetry plotted against the mean by both methods.

\section{Discussion}

Doppler ultrasonography has proved to be a reliable method for the non-invasive quantification of the peak pressure gradient in aortic stenosis. ${ }^{6-8}$ The lack of any significant difference betweeen the peak pressure gradients determined by the Doppler technique and at catheterisation in this study further supports the reliability of the Doppler technique. The peak pressure difference has, however, some important drawbacks. It is not widely used in hydraulic formulas, which makes it inconvenient as a measurement of the severity of stenosis. Measurements from pressure curves are not as easy to do as measurements from velocity recordings and they may become obscured by pressure oscillations if fluid filled catheters are used. In addition, considerable errors may follow minor deviations of timing when pressure curves from different heart beats are superimposed.

The peak to peak pressure difference, which is routinely measured at catheterisation, mainly because it is convenient, cannot be measured by the Doppler technique because the peaks of the left ventricular and aortic pressure curves occur at different times. Replacing the peak to peak pressure difference with the Doppler derived peak pressure difference may greatly overestimate the severity of the stenosis, particularly in patients with moderate stenosis or increased flow (or both). The peak pressure gradient exceeded the peak to peak gradient by $48 \mathrm{~mm} \mathrm{Hg}$ in one patient. Differences of this magnitude have also been recorded by others. ${ }^{5}$

The mean pressure difference reflects the changes of the pressure difference during systole and may be used to estimate the severity of stenosis. In addition, there is usually close agreement between the mean pressure gradients acquired from adequate Doppler 
recordings and those obtained at catheterisation. ${ }^{568}$ Determination of the mean pressure differences from Doppler recordings, however, requires measurements of instantaneous flow velocities at short intervals throughout systole. The velocities then have to be squared and the area of the resulting (pressure) curve calculated. ${ }^{6}$ This procedure is time consuming and impractical for clinical purposes. Zhang and Nitter-Hauge suggested a new formula to facilitate calculation of the mean pressure difference, ${ }^{10}$ but the mean flow velocity is still needed in their formula.

The relation between the mean and peak pressure difference depends on the configuration of the pressure curve. Theoretically, the curve may be triangular at one extreme and rectangular at the other, the mean pressure difference ranging between $1 / 3$ and 1 of the peak pressure difference. ${ }^{10}$ In practice, however, the configuration of the curve rarely gets near these extremes. Our results show that the pressure drop curve may be regarded as a simple sine wave.

Estimation of the mean pressure difference from the peak pressure difference by the formula provided may simplify the comparison of non-invasive and catheterisation data. Most importantly the accuracy of the Doppler derived mean pressure difference determined by the formula is not reduced.

This study was supported by grants from the University of Umeå.

\section{References}

1 Hatle L, Angelsen BA, Tromsdal A. Non-invasive assessment of aortic stenosis by Doppler ultrasound. Br Heart $\mathcal{F}$ 1980;43:284-92.

2 Stamm RB, Martin RP. Quantification of pressure gra- dients across stenotic valves by Doppler ultrasound. f Am Coll Cardiol 1983;2:707-18.

3 Teien D, Eriksson P. Quantification of transvalvular pressure differences in aortic stenosis by Doppler ultrasound. Int $f$ Cardiol 1985;7:121-6.

4 Hatle L. Assessment of aortic stenosis with Doppler ultrasound. Int $\mathcal{F}$ Cardiol 1985;7:127-8.

5 Krafchek J, Robertson JH, Radford M, Adams D, Kisslo J. A reconsideration of Doppler assessed gradients in suspected aortic stenosis. Am Heart $\mathcal{f}$ 1985;110:765-73.

6 Hegrenæs L, Hatle L. Aortic stenosis in adults; noninvasive estimation of pressure differences by continuous wave Doppler echocardiography. Br Heart $\mathcal{f}$ 1985;54:396-404.

7 Skjaerpe T, Hegrenaes L, Hatle L. Noninvasive estimation of valve area in patients with aortic stenosis by Doppler ultrasound and two-dimensional echocardiography. Circulation 1985;72:810-8.

8 Currie PJ, Seward JB, Reeder GS, et al. Continuouswave Doppler echocardiographic assessment of severity of calcific aortic stenosis: a simultaneous Doppler-catheter correlative study in 100 adult patients. Circulation 1985;71:1162-9.

9 Zhang Y, Myhre E, Nitter-Hauge S. Noninvasive quantification of the aortic valve area in aortic stenosis by Doppler echocardiography. Eur Heart $\mathcal{f}$ 1985;6:992-8.

10 Zhang Y, Nitter-Hauge S. Determination of the mean pressure gradient in aortic stenosis by Doppler echocardiography. Eur Heart f 1985;6:999-1005.

11 Gorlin R, Gorlin SG. Hydraulic formula for calculation of the area of the stenotic mitral valve, other cardiac valves, and central circulatory shunts. $\mathrm{Am}$ Heart $\mathcal{F}$ 1951;41:1-29.

12 Cannon SR, Richards KL, Crawford M. Hydraulic estimation of stenotic orifice area: a correction of the Gorlin formula. Circulation 1985;71:1170-8.

13 Grossman W, Dexter L. Profiles in valvular heart disease. In: Grossman W, ed. Cardiac catheterization and angiography. 2nd ed. Philadelphia: Lea and Febiger, 1980:305-24.

14 Bland JA, Altman DG. Statistical methods for assessing agreement between two methods of clinical measurement. Lancet 1986;i:307-10. 